\title{
ChemComm
}

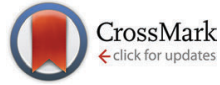

Cite this: Chem. Commun., 2015, 51, 9837

Received 1st April 2015, Accepted 14th May 2015

DOI: $10.1039 / \mathrm{c5cc02701b}$

www.rsc.org/chemcomm

\section{One-pot selective synthesis of a fullerene bisadduct for organic solar cell applications $\dagger$}

\author{
Bolong Zhang, Jegadesan Subbiah, Yu-Ying Lai, Jonathan M. White, David J. Jones \\ and Wallace W. H. Wong*
}

\begin{abstract}
A single isomer of fullerene bisadduct, $\mathrm{PC}_{61} \mathrm{PF}$, was obtained from commercially available fullerene derivative, $\mathrm{PC}_{61} \mathrm{BM}$, in one pot over two steps. The tether-directed remote functionalization approach provided a very simple and fast method to produce a single isomer of fullerene bisadduct with good yield and easy purification. Bulk heterojunction organic solar cells containing the bisadduct was fabricated and tested.
\end{abstract}

Over the past decade, organic solar cells (OSCs) has been a hot topic of research as an emerging renewable energy technology. In comparison with conventional devices, such as silicon solar cells, OSC technology promises lightweight flexible devices that can be produced at low cost through roll-to-roll printing methods. ${ }^{1}$ One specific type of OSC is the bulk-heterojunction (BHJ) solar cell which contains a blend of electron donor and acceptor materials in its active layer. Among electron acceptor materials, fullerenes are one of the most attractive compounds, due to their reversible reduction behavior, ${ }^{2}$ good electron transport properties ${ }^{3}$ and easily functionalized structures. ${ }^{4}$ Numerous fullerene derivatives have been reported and used as effective electron acceptor materials in OSC devices, such as $[6,6]$-phenyl- $\mathrm{C}_{61}$-butyric acid methyl ester $\left(\mathrm{PC}_{61} \mathrm{BM}\right)^{5}$ and indene $\mathrm{C}_{60}$ bisadduct $\left(\mathrm{IC}_{60} \mathrm{BA}\right){ }^{6}$

The power convention efficiency (PCE) of OSCs can be optimized by adjusting the device parameters of open-circuit voltage $\left(V_{\mathrm{oc}}\right)$, short-circuit current density $\left(J_{\mathrm{sc}}\right)$ and fill factor $(\mathrm{FF}){ }^{7}$ In particular, the $V_{\mathrm{oc}}$ is relatively easy to control by tuning the highest occupied molecular orbital (HOMO) energy level of donor material and the lowest unoccupied molecular orbital (LUMO) energy level of acceptor material. ${ }^{8} \mathrm{~A}$ common strategy to increase the voltage is to elevate the LUMO energy level of the fullerene acceptor and this is normally achieved by attaching additional substituents to the fullerene core. ${ }^{9}$ There has been a few examples of fullerene bisadducts employed in

School of Chemistry, University of Melbourne Bio21 Institute, 30 Flemington Rd, Parkville, Victoria 3010, Australia. E-mail: wwhwong@unimelb.edu.au

$\dagger$ Electronic supplementary information (ESI) available: Details on the synthesis procedure and characterization of the materials as well as device fabrication and testing. CCDC 1057267. For ESI and crystallographic data in CIF or other electronic format see DOI: 10.1039/c5cc02701b
OSC devices but these bisadduct materials are typically regioisomer mixtures. ${ }^{10-14}$ There has been a handful of studies looking at the effect of regioisomers on device performance thus far. ${ }^{15-18}$ In particular, our group isolated a crystalline single isomer of the indene $\mathrm{C}_{70}$ bisadduct $\left(\mathrm{IC}_{70} \mathrm{BA}\right)$ and examined its device performance. ${ }^{19}$ While the results were promising, the single isomer was obtained by careful chromatographic separation which meant that the production of material was both time consuming and difficult to scale up.

In order to target pure fullerene bisadduct materials in a more efficient manner, we decided to investigate a regioselective synthesis method, namely tether-directed remote functionalization. ${ }^{20,21}$ In general, this idea aims at increasing the regioselectivity of reactions on the fullerene surface by using a linker between the reactive head groups. This method has been successfully demonstrated on both $\mathrm{C}_{60}$ and $\mathrm{C}_{70}$ substrates and perfect regioselectivity as well as stereoselectivity has been achieved. ${ }^{22-24}$ In this work, the tether-directed functionalization approach was used to obtain selectively a $\mathrm{C}_{60}$ bisadduct, $N$-methyl-phenyl- $\mathrm{C}_{61}$-propyl-2-fulleropyrrolidine $\left(\mathrm{PC}_{61} \mathrm{PF}\right)$. A range of characterization methods were performed to show that the final product was a single regioisomer. To compare the properties of the single isomer with an isomeric mixture, a non-tethered $\mathrm{PC}_{61} \mathrm{BM}$-based fulleropyrrolidine $\left(\mathrm{PC}_{61} \mathrm{BM}-\mathrm{FP}\right)$ was also prepared (Fig. 1). The single isomer of $\mathrm{PC}_{61} \mathrm{PF}$ as well as $\mathrm{PC}_{61} \mathrm{BM}-\mathrm{FP}$ and $\mathrm{PC}_{61} \mathrm{BM}$ were used in $\mathrm{BHJ}$ OSC devices to examine their photovoltaic performance.

The fullerene bisadduct $\mathrm{PC}_{61} \mathrm{PF}$ was synthesized from $\mathrm{PC}_{61} \mathrm{BM}$ in one pot over two steps in 53\% yield (Fig. 2a). Firstly, diisobutylaluminium hydride (DIBAL) was added dropwise to a stirred solution of $\mathrm{PC}_{61} \mathrm{BM}$ at $-78{ }^{\circ} \mathrm{C}$ in toluene under nitrogen atmosphere. After stirring for one hour, the reaction was quenched with methanol to give the crude aldehyde intermediate. Solvents were removed under vacuum from the reaction vessel and the aldehyde was used in the next step without isolation. The aldehyde was heated with $N$-methylglycine in 1,2-dichlorobenzene (o-DCB) at $180{ }^{\circ} \mathrm{C}$ with to form $\mathrm{PC}_{61} \mathrm{PF}$. The 1,3-dipolar cycloaddition step was monitored by thin layer chromatography $\left(\mathrm{SiO}_{2}\right.$, toluene) to optimize the formation of the fulleropyrrolidine. The $\mathrm{PC}_{61} \mathrm{PF}$ 


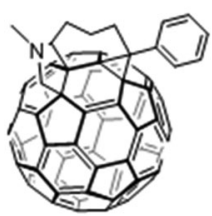

$\mathrm{PC}_{61} \mathrm{PF}$

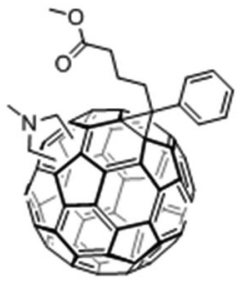

$\mathrm{PC}_{61} \mathrm{BM}-\mathrm{FP}$

(Mixture of regioisomers)

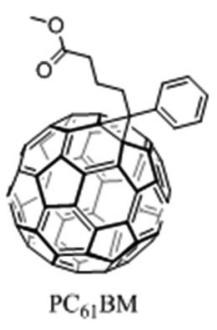

$\mathrm{PC}_{61} \mathrm{BM}$
Fig. 1 Chemical structures of single isomer, $\mathrm{PC}_{61} \mathrm{PF}$, bisadduct isomeric mixture, $\mathrm{PC}_{61} \mathrm{BM}-\mathrm{FP}$, and widely used $\mathrm{PC}_{61} \mathrm{BM}$.
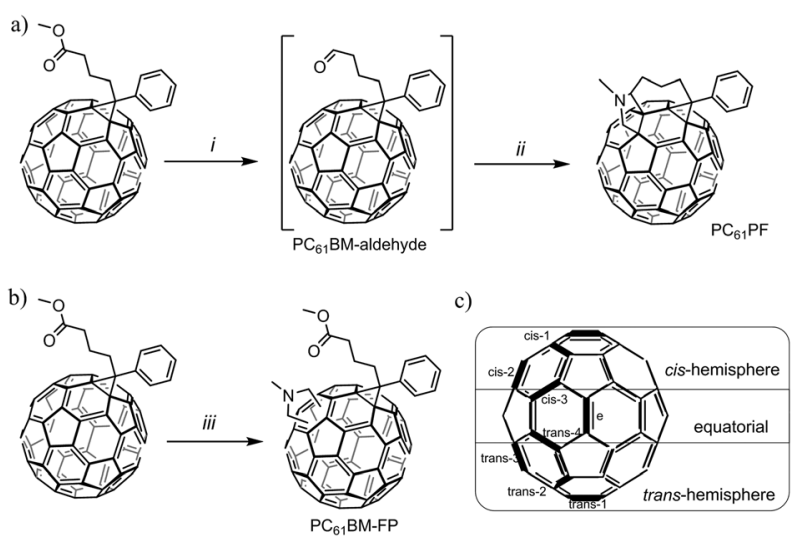

Fig. 2 Synthesis of fullerene bisadducts (a) $P C_{61} P F$ and (b) $P C_{61} B M-F P$ with reaction conditions: (i) DIBAL, $-78{ }^{\circ} \mathrm{C}$, toluene, stir $1 \mathrm{~h}$; (ii) $\mathrm{N}$-methylglycine, o-DBC, reflux $1.5 \mathrm{~h}$; (iii) $\mathrm{N}$-methylglycine, o-DBC, reflux 3 days. The nomenclature for fullerene bisadducts illustrated in (c).

product was purified by flash chromatography $\left(\mathrm{SiO}_{2}\right.$, toluene). The purity of the product was analyzed using high performance liquid chromatography with a Cosmosil Buckyprep-D column which indicated the sample contained one major product (see $\mathrm{ESI} \dagger$ ). The isomeric mixture $\mathrm{PC}_{61} \mathrm{BM}-\mathrm{FP}$ was synthesized from $\mathrm{PC}_{61} \mathrm{BM}$ and $N$-methylglycine in $29 \%$ yield (Fig. $2 \mathrm{~b}$ ).

The 1,3-dipolar cycloaddition on fullerenes usually results in reaction on the double bonds between six-member rings (namely the $[6,6]$ bonds). In the case of $\mathrm{C}_{60}$ bisadducts, there are eight potential reacting position for the second substituent, which can result in at least eight isomers (Fig. 2c). Due to the length of the linker on $\mathrm{PC}_{61} \mathrm{PF}$, possible regioisomers should be limited to the cis-hemisphere of the molecule. Notably, potential products will contain stereoisomers because of the flexibility of the linker.

To predict the configuration of the final product, theoretical calculations were carried out with Gaussian 09, applying density functional theory at the B3LYP level. The basis set of 6-311G, with polarization functions $(\mathrm{d}, \mathrm{p})$, was used in the calculations. Considering both the length of the three-member carbon chain and the result of theoretical calculation, the possible positions of the pyrrolidine substituent were narrowed down to the cis-1, cis-2 and cis-3 positions of $\mathrm{C}_{60}$. Apart from regioisomers, geometric isomers are also possible at the cis-1 position, namely

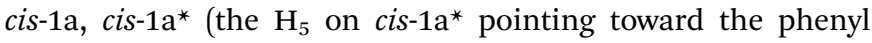
group) and cis-1b (Fig. 3a). The relative energy of the transition
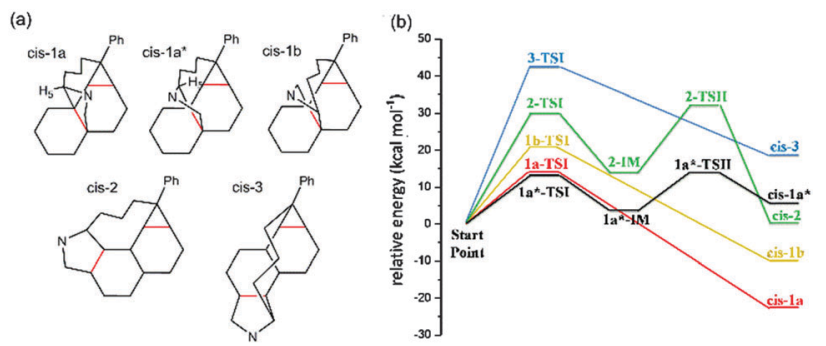

Fig. 3 (a) Five possible configurations of $\mathrm{PC}_{61} \mathrm{PF}$ and (b) theoretical calculation results showing the relative energy of start point, transition states and final products of the four possible configurations.

state of the 1,3-dipolar cycloaddition as well as the energy of the start material and possible products were calculated (Fig. 3b and Table S1, ESI $\dagger$ ). The starting point of the calculation was the azomethine intermediate which originated from the reaction between the aldehyde and the amino acid (see ESI $\dagger$ for details). The activation barriers in $o$-DCB solvent environment are estimated to be $14.03 \mathrm{kcal} \mathrm{mol}^{-1}$ for cis-1a, $21.10 \mathrm{kcal} \mathrm{mol}^{-1}$ for $c i s-1 \mathrm{~b}$ and $42.67 \mathrm{kcal} \mathrm{mol}^{-1}$ for cis-3. On the other hand, stepwise cycloaddition is suggested for $c i s-1 \mathrm{a}^{*}$ and cis-2 via the intermediates $1 \mathrm{a}^{*}$-IM and 2-IM with the rate-limiting barriers of 13.39 and $29.76 \mathrm{kcal} \mathrm{mol}^{-1}$, respectively. Based on the computational results, $c i s-1 \mathrm{a}$ and $c i s-1 \mathrm{a}^{*}$ are the kinetic products with the lowest activation energy, while cis-1a is also the thermodynamic product with the deepest product Gibbs free energy. These theoretical calculations were used to guide the structural assignments.

Further data on structure assignment was obtained with UV-vis absorption spectroscopy (Fig. 4). It is known that the UV-vis absorption spectrum of fullerene derivatives contains distinct bands and features for different regioisomers. This is related to the variations of the conjugated surface of the fullerene derivatives. The UV-vis spectrum of $\mathrm{PC}_{61} \mathrm{PF}$ showed an onset of $730 \mathrm{~nm}$ and a peak at $440 \mathrm{~nm}$ (Fig. 4). These features are similar to that observed for a reported $\mathrm{C}_{60}$-benzyne bisadduct with cis-1 configuration. ${ }^{25}$ This observation is in agreement with the assignments in the NMR experiments and in the theoretical calculations.

The ${ }^{1} \mathrm{H}$-NMR spectrum of the single isomer of $\mathrm{PC}_{61} \mathrm{PF}$ was well-resolved (Fig. 5a). Most interestingly, the six protons on the

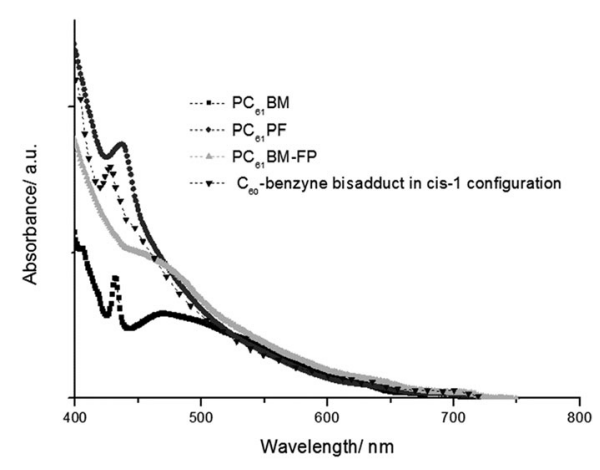

Fig. 4 The UV-vis absorption spectrum of $\mathrm{PC}_{61} \mathrm{BM}, \mathrm{PC}_{61} \mathrm{PF}$, the mixture of $\mathrm{PC}_{61} \mathrm{BM}-\mathrm{FP}$ and $\mathrm{C}_{60}$-benzyne bisadducts in cis-1 configuration. 


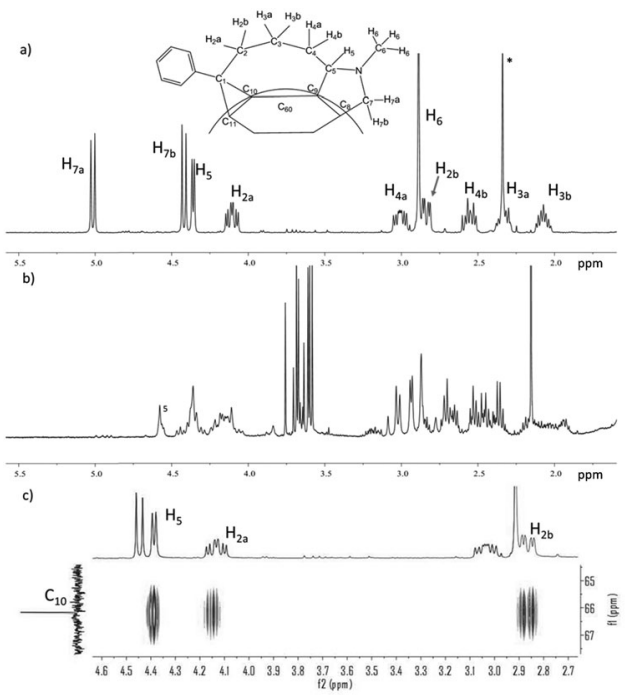

Fig. 5 (a) $1 \mathrm{H}$ NMR spectrum of $\mathrm{PC}_{61} \mathrm{PF}$ and its simplified structure, (b) ${ }^{1} \mathrm{H}$ NMR spectrum of $\mathrm{PC}_{61} \mathrm{BM}-\mathrm{FP}$ mixed isomers and (c) $\mathrm{HMBC}$ spectrum of $\mathrm{PC}_{61} \mathrm{PF}$ showing the long distance coupling between $\mathrm{C}_{10}$ and $\mathrm{H}_{2 a}, \mathrm{H}_{2 b}, \mathrm{H}_{5}$.

propyl linker all have different chemical shifts in the 1 to $5 \mathrm{ppm}$ region of the NMR spectrum. These separated proton resonances strongly supported the fact that the propyl linker was locked in a fused cyclic system with the protons residing in different environments above the fullerene surface. This was also indicative of the regioselectivity of the reaction. Further indication of selectivity was evident by comparing the ${ }^{1} \mathrm{H}$ NMR spectrum of the bisadduct mixture $\mathrm{PC}_{61} \mathrm{BM}-\mathrm{PF}$ to that of the $\mathrm{PC}_{61} \mathrm{PF}$ sample (Fig. $5 \mathrm{a}$ and $\mathrm{b}$ ). Full assignments of the proton and carbon resonances of the substituents on $\mathrm{PC}_{61} \mathrm{PF}$ was achieved using correlation spectroscopy and heteronuclear single quantum coherence spectroscopy 2D-NMR experiments (see ESI $\dagger$ ). With these assignments, it was possible to use heteronuclear multiple-bond correlation spectroscopy (HMBC) experiment to aid in the structural determination. By focusing on the $\mathrm{C}_{10}$ carbon, it was apparent that there was coupling with protons $\mathrm{H}_{5}, \mathrm{H}_{2 \mathrm{a}}$ and $\mathrm{H}_{2 \mathrm{~b}}$ (Fig. 5c). This correlation suggested a structural configuration that matched the cis-1a isomer. In addition, the configuration of the cis-1b isomer would lead to coupling of carbon $\mathrm{C}_{10}$ with protons $\mathrm{H}_{7 \mathrm{a}}$ and $\mathrm{H}_{7 \mathrm{~b}}$. This was not observed in the HMBC experiment.

The relative configuration of the $\mathrm{PC}_{61} \mathrm{PF}$ material was confirmed by single crystal X-ray analysis (Fig. 5). Good quality single crystals were obtained by recrystallization from $o$-DCB and petroleum spirit $40-60{ }^{\circ} \mathrm{C}$. Crystals of $\mathrm{PC}_{61} \mathrm{PF}$ consisted of a racemic mixture of the cis-1a isomer with $o$-DCB solvent incorporated in the crystal structure. The packing diagram of crystalline $\mathrm{PC}_{61} \mathrm{PF}$ showed alternating rows of enantiomeric pairs with $o$-DCB filling gaps between $\mathrm{PC}_{61} \mathrm{PF}$ molecules. (Fig. 6). The nearest distance between fullerenes is $3.38 \AA$.

With the molecular structure of $\mathrm{PC}_{61} \mathrm{PF}$ solved, relevant data on its materials properties were acquired. To estimate the LUMO energy level of the material, cyclic voltammetry was performed (Fig. S14, ESI $\dagger$ ). Data was also obtained for the $\mathrm{PC}_{61} \mathrm{BM}-\mathrm{FP}$ mixture and $\mathrm{PC}_{61} \mathrm{BM}$ for comparison (Table 1). The fullerene bisadducts $\mathrm{PC}_{61} \mathrm{PF}$ and $\mathrm{PC}_{61} \mathrm{BM}-\mathrm{FP}$ had relatively higher LUMO
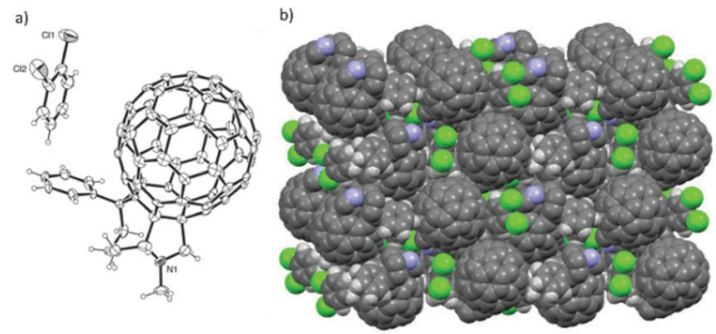

Fig. 6 Structure obtained by $\mathrm{X}$-ray crystallography of $\mathrm{PC}_{61} \mathrm{PF}$ grown from o-DCB and petroleum spirit: (a) thermal ellipsoid illustration, (b) packing diagram where disordered atoms have been omitted for clarity.

Table 1 Characterization results of $\mathrm{PC}_{61} \mathrm{PF}, \mathrm{PC}_{61} \mathrm{BM}-\mathrm{FP}$ and $\mathrm{PC}_{61} \mathrm{BM}$

\begin{tabular}{lllll}
\hline $\begin{array}{l}\text { Electron acceptor } \\
\text { materials }\end{array}$ & $\begin{array}{l}E_{12}^{\mathrm{red} a} \\
(\mathrm{eV})\end{array}$ & $\begin{array}{l}E_{\mathrm{LUMO}}{ }^{b} \\
(\mathrm{eV})\end{array}$ & $\begin{array}{l}\text { UV-vis abs } \\
\lambda_{\max }{ }^{c}(\mathrm{~nm})\end{array}$ & $\begin{array}{l}T_{\mathrm{d}}{ }^{d} \\
\left({ }^{\circ} \mathrm{C}\right)\end{array}$ \\
\hline $\mathrm{PC}_{61} \mathrm{PF}$ & -1.04 & -3.76 & $437(8.7)$ & 428 \\
$\mathrm{PC}_{61} \mathrm{BM}-\mathrm{FP}$ & -1.15 & -3.65 & $463(4.7)$ & 379 \\
$\mathrm{PC}_{61} \mathrm{BM}$ & -0.95 & -3.85 & $432(4.1)$ & 432
\end{tabular}

${ }^{a}$ Half-wave reduction potential from cyclic voltammetry. ${ }^{b} E_{\text {LUMO }}=$ $-\left(E_{1 / 2}^{\text {red }}+4.8\right) \mathrm{eV} .{ }^{c}$ Absorption coefficient $\left(\times 10^{3} \mathrm{M}^{-1} \mathrm{~cm}^{-1}\right)$ in brackets. ${ }^{d}$ Decomposition temperature ( $5 \%$ weight loss).

energy levels of $-3.76 \mathrm{eV}$ and $-3.66 \mathrm{eV}$ respectively compared to that of $\mathrm{PC}_{61} \mathrm{BM}$ at $-3.85 \mathrm{eV}$. This was the predicted outcome and improved open circuit voltages were expected for devices using the bisadducts as the electron acceptor material. Thermal analysis, such as differential scanning calorimetry and thermo gravimetric analysis, were also performed on the materials (Fig. S9 to S13, ESI $\dagger$ ). No phase transitions were observed up to $300{ }^{\circ} \mathrm{C}$ and the decomposition temperature ( $5 \%$ weight loss) for fullerene compounds $\mathrm{PC}_{61} \mathrm{PF}$ and $\mathrm{PC}_{61} \mathrm{BM}$ was more than $400{ }^{\circ} \mathrm{C}$ (Table 1).

The final part of the study was to compare the solar cell performance of the single isomer $\mathrm{PC}_{61} \mathrm{PF}$ material with $\mathrm{PC}_{61} \mathrm{BM}$ and the isomer mixture $\mathrm{PC}_{61} \mathrm{BM}-\mathrm{FP}$. Bulk heterojunction devices were made in the following geometry: ITO/PEDOT:PSS/active layer/Ca/Al, in which the active layer was a blend of poly(3-hexylthiophene) P3HT and each acceptor materials with the ratio of $1: 1$ by weight (Fig. S15, ESI $\dagger$ ). The processing solvent was $o$-DCB and the thicknesses of the devices was optimized by adjusting solution concentration and spin coating speed (see ESI $\dagger$ ). The device performance parameters are summarized in Table 2. It is clear that the $V_{\mathrm{oc}}$ of devices increased significantly, from 0.58 to $0.70 \mathrm{~V}$, when using $\mathrm{PC}_{61} \mathrm{PF}$ instead $\mathrm{PC}_{61} \mathrm{BM}$ as acceptor material (Fig. S15, ESI $\dagger$ ). This is in agreement with previous literature reports of using fullerene bisadduct materials to boost the $V_{\text {oc. }}{ }^{19}$ Comparing the devices containing $\mathrm{PC}_{61} \mathrm{PF}$ and the isomer mixture $\mathrm{PC}_{61} \mathrm{BM}-\mathrm{FP}$, both $J_{\mathrm{sc}}$ and $\mathrm{FF}$ were higher for the $\mathrm{PC}_{61} \mathrm{PF}$ devices (Table 2). A reason for this observation is the pure single isomer material $\mathrm{PC}_{61} \mathrm{PF}$ should have better charge transport properties than the isomer mixture $\mathrm{PC}_{61} \mathrm{BM}-\mathrm{FP}$ (vide infra). The external quantum efficiency (EQE) spectrum of the devices were obtained to investigate the photo-current contribution of the active layers in OPV devices. The better performing device containing $\mathrm{PC}_{61} \mathrm{PF}$ showed significant photocurrent enhancement from $300 \mathrm{~nm}$ to $630 \mathrm{~nm}$ comparing to the devices containing 
Table 2 The performance of devices based on $\mathrm{PC}_{61} \mathrm{PF}, \mathrm{PC}_{61} \mathrm{BM}-\mathrm{FP}$ and $\mathrm{PC}_{61} \mathrm{BM}$ with $\mathrm{P} 3 \mathrm{HT}$ (1:1 blend ratio by weight)

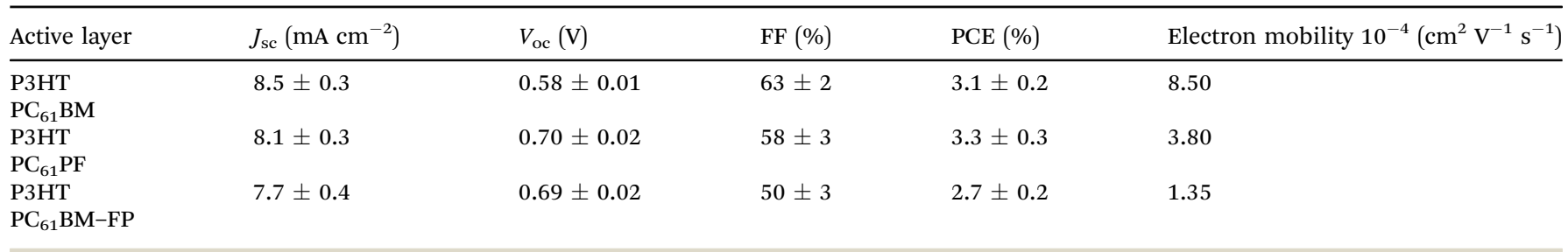

$\mathrm{PC}_{61} \mathrm{BM}-\mathrm{FP}$ (Fig. S15, ESI $\dagger$ ). The maximum EQE of device containing $\mathrm{PC}_{61} \mathrm{PF}$ was $63 \%$ at $500 \mathrm{~nm}$ which was higher than the maximum $\mathrm{EQE}$ of $59 \%$ in the devices containing $\mathrm{PC}_{61} \mathrm{BM}-$ FP. The EQE data of the $\mathrm{PC}_{61} \mathrm{BM}$ device showed slightly higher efficiency across the spectrum. This could be attributed to the higher charge mobility of the $\mathrm{PC}_{61} \mathrm{BM}$ material (vide infra). It is interesting to note that the higher $E_{\text {LUMO }}$ measured in electrochemical experiments for $\mathrm{PC}_{61} \mathrm{BM}-\mathrm{FP}$ was not reflected in the $V_{\text {oc }}$ of devices. Two factors may account for this observation. The $\mathrm{PC}_{61} \mathrm{BM}-\mathrm{FP}$ material consisted of a mixture of isomers and there could be energy level variations between the various species present in the sample. Another way to look at these results is to consider the variation in device optimization. Assuming the electrochemical data gave a true reflection on the $E_{\text {LUMO }}$ of the $\mathrm{PC}_{61} \mathrm{BM}-\mathrm{FP}$ material, then the $V_{\mathrm{oc}}$ of device should be higher. Device optimizations, such as blend ratios and processing methods, have been shown to affect $V_{\text {oc}}$. It may be possible to improve the $V_{\mathrm{oc}}$ of the $\mathrm{PC}_{61} \mathrm{BM}-\mathrm{FP}$ device through extensive device optimization.

To examine the charge transport behavior of the acceptor materials in the bulk heterojunction, the space charge limited current (SCLC) measurements were obtained (Fig. S16, ESI $\dagger$ ). The electron mobility in devices containing $\mathrm{PC}_{61} \mathrm{PF}$ and $\mathrm{PC}_{61} \mathrm{BM}-\mathrm{FP}$ were calculated to be $3.80 \times 10^{-4}$ and $1.35 \times 10^{-4} \mathrm{~cm}^{2} \mathrm{~V}^{-1} \mathrm{~s}^{-1}$ respectively. This result showed that the single isomer of fullerene bisadduct had better electron mobility than the isomer mixture $\mathrm{PC}_{61} \mathrm{BM}-\mathrm{FP}$ in these $\mathrm{BHJ}$ devices. In addition, the hole mobility of the P3HT from SCLC was previously measured at $3.30 \times 10^{-4} \mathrm{~cm}^{2} \mathrm{~V}^{-1} \mathrm{~s}^{-1}$ in BHJ devices. ${ }^{26}$ This meant that more balanced charge transport occurred in the P3HT-PC ${ }_{61} \mathrm{PF}$ blend films. The surface morphology of the films were examined using atomic force microscopy. Nanoscale features were observed in the topography and phase images and were similar in all P3HT:fullerene blend films (Fig. S17, ESI $\dagger$ ). This means the difference in the solar cell device performance between the $\mathrm{PC}_{61} \mathrm{PF}$ and $\mathrm{PC}_{61} \mathrm{BM}-\mathrm{FP}$ materials can be attributed to their electron mobility in the $\mathrm{BHJ}$ blends.

Regioselective synthesis of a single $\mathrm{C}_{60}$ bisadduct isomer, $\mathrm{PC}_{61} \mathrm{PF}$, was achieved efficiently in a one-pot two step procedure from commercially available $\mathrm{PC}_{61} \mathrm{BM}$. The tether-directed functionalization strategy was applied successfully to control the regioselectivity of the final product in the cis-1 configuration. In $\mathrm{BHJ}$ solar cell devices, the single isomer $\mathrm{PC}_{61} \mathrm{PF}$ outperformed the isomeric mixture $\mathrm{PC}_{61} \mathrm{BM}-\mathrm{FP}$ and was on par with $\mathrm{PC}_{61} \mathrm{BM}$. Further research in modifying the properties, such as solubility and crystallinity, of $\mathrm{PC}_{61} \mathrm{PF}$ derivatives by changing the amino acid in the synthesis process is currently in progress.

This work was made possible by support from the Australian Renewable Energy Agency which funds the project grants within the Australian Centre for Advanced Photovoltaics. WWHW is supported by an Australian Research Council Future Fellowship (FT130100500). Responsibility for the views, information, or advice herein is not accepted by the Australian Government.

\section{Notes and references}

1 R. Søndergaard, M. Hösel, D. Angmo, T. T. Larsen-Olsen and F. C. Krebs, Mater. Today, 2012, 15, 36-49.

2 L. Echegoyen and L. E. Echegoyen, Acc. Chem. Res., 1998, 31, 593-601.

3 P. Bracher and D. Schuster, in Fullerenes: From Synthesis to Optoelectronic Properties, ed. D. Guldi and N. Martin, Springer, Netherlands, 2002, ch. 6 , vol. 4, pp. 163-212.

4 F. Langa and J.-F. Nierengarten, Fullerenes: principles and applications, Royal Society of Chemistry, 2007.

5 G. Yu, J. Gao, J. Hummelen, F. Wudl and A. Heeger, Science, 1995, 270, 1789-1790.

6 Y. He, H.-Y. Chen, J. Hou and Y. Li, J. Am. Chem. Soc., 2010, 132, 1377-1382.

7 H. Hoppe and N. S. Sariciftci, J. Mater. Res., 2004, 19, 1924-1945.

8 G. Dennler, M. C. Scharber and C. J. Brabec, Adv. Mater., 2009, 21, 1323-1338.

9 M. J. van Eis, P. Seiler, L. A. Muslinkina, M. Badertscher, E. Pretsch, F. Diederich, R. J. Alvarado, L. Echegoyen and I. P. Nunez, Helv. Chim. Acta, 2002, 85, 2009-2055.

10 Y.-Y. Lai, Y.-J. Cheng and C.-S. Hsu, Energy Environ. Sci., 2014, 7, 1866-1883.

11 C.-Z. Li, H.-L. Yip and A. K. Y. Jen, J. Mater. Chem., 2012, 22, 4161-4177.

12 H.-L. Yip and A. K. Y. Jen, Energy Environ. Sci., 2012, 5, 5994-6011.

13 Y. Li, Chem. - Asian J., 2013, 8, 2316-2328.

14 T. Umeyama and H. Imahori, J. Mater. Chem. A, 2014, 2, 11545-11560. 15 X. Meng, G. Zhao, Q. Xu, Z. a. Tan, Z. Zhang, L. Jiang, C. Shu, C. Wang and Y. Li, Adv. Funct. Mater., 2014, 24, 158-163.

16 Y. Matsuo, J. Kawai, H. Inada, T. Nakagawa, H. Ota, S. Otsubo and E. Nakamura, Adv. Mater., 2013, 25, 6266-6269.

17 S. Kitaura, K. Kurotobi, M. Sato, Y. Takano, T. Umeyama and H. Imahori, Chem. Commun., 2012, 48, 8550-8552.

18 M.-H. Liao, Y.-Y. Lai, Y.-Y. Lai, Y.-T. Chen, C.-E. Tsai, W.-W. Liang and Y.-J. Cheng, ACS Appl. Mater. Interfaces, 2014, 6, 996-1004.

19 W. W. H. Wong, J. Subbiah, J. M. White, H. Seyler, B. L. Zhang, D. J. Jones and A. B. Holmes, Chem. Mater., 2014, 26, 1686-1689.

20 R. Breslow, Acc. Chem. Res., 1980, 13, 170-177.

21 L. Isaacs, R. F. Haldimann and F. Diederich, Angew. Chem., Int. Ed., 1994, 33, 2339-2342.

22 C. Thilgen and F. Diederich, C. R. Chim., 2006, 9, 868-880.

23 W. W. H. Wong and F. Diederich, Chem. - Eur. J., 2006, 12, 3463-3471.

24 S. Sergeyev and F. Diederich, Angew. Chem., Int. Ed., 2004, 43, 1738-1740.

25 Y. Nakamura, N. Takano, T. Nishimura, E. Yashima, M. Sato, T. Kudo and J. Nishimura, Org. Lett., 2001, 3, 1193-1196.

26 C. Goh, R. J. Kline, M. D. McGehee, E. N. Kadnikova and J. M. J. Fréchet, Appl. Phys. Lett., 2005, 86, 122110. 